\title{
Effect of Supplemental Sericea Lespedeza Pellets on Internal Parasite Infection and Nutritional Status of Grazing Goats
}

Tiffani Hamilton ${ }^{1}$, Thomas Terrill ${ }^{1}$, Dill Sandeep Kommuru ${ }^{1}$, Aqiyla Rivers ${ }^{1}$, Jorge Mosjidis ${ }^{2}$, James Miller ${ }^{3}$, Chris Drake ${ }^{4}$, Irene Mueller-Harvey ${ }^{4}$ and Joan Burke ${ }^{5}$

1. Agricultural Research Station, Fort Valley State University, Fort Valley, GA 31030, USA

2. Department of Agronomy and Soils, Auburn University, Auburn, AL 36849, USA

3. Department of Pathobiological Sciences, Louisiana State University, Baton Rouge, LA 70803, USA

4. School of Agriculture, Policy and Development, University of Reading, Reading RG6 6AT, UK

5. United States Department of Agriculture, Agricultural Research Service, Booneville, AR 72927, USA

\begin{abstract}
Feeding pelleted sericea lespedeza (SL; Lespedeza cuneata) on pasture can reduce gastrointestinal nematode (GIN) and coccidia (Eimeria spp.) infection in sheep and goats, but effects on nutritional status are unclear. Therefore, a study was completed comparing yearling goats grazing grass pasture supplemented with SL or non-condensed tannins (CT) commercial pellets (control group), respectively, at $1.5 \%$ of body weight for 14 weeks, and then after 14 weeks, they were only fed with non-CT pellets at $2.5 \%$ of body weight for additional six weeks. Animal body weight was measured at the start of the trial, the 7th week, 14th week and end of the trial. Fecal samples were taken weekly to determine GIN egg output (fecal egg count; FEC) and coccidial oocyst production (fecal oocyst count; FOC). Blood samples (to determine packed cell volume; PCV) were taken weekly to monitor anemia status of the goats, and on days 0,98 and 137 to determine aspartate aminotransferase (AST), alanine aminotransferase (ALT) and creatine kinase (CK). The study revealed that supplemental SL leaf meal pellets had no effect on FEC, but reduced FOC $(P<0.05)$ and improved FAMACHA ${ }^{\odot}$ scores $(P<0.001)$ in the goats, and the SL supplemented goats tended to gain more weight $(P=0.07)$ than control animals during the first $49 \mathrm{~d}$, following initiation of pellet feeding. There were no treatment effects on enzymes related to liver function or muscle turnover (AST, ALT and CK), suggesting that there was no muscle damage due to long-term feeding of SL pellets. In conclusion, feeding supplemental SL pellets at $1.5 \%$ of body weight on pasture may be a viable strategy for improving health and productivity of yearling goats.
\end{abstract}

Key words: Coccidia, gastrointestinal nematodes, goats, micronutrient, sericea lespedeza.

\section{Introduction}

Gastrointestinal parasite infections are the greatest threat to economic sheep and goat production in both temperate and tropical countries worldwide, causing decreased feed intake, birth and body weights, growth rate, fertility, milk yield and carcass quality, as well as increased mortality $[1,2]$. As synthetic anti-parasitic remedies are no longer considered a sustainable long-term option for parasite control, due to rapidly

Corresponding author: Thomas Terrill, associate professor, research field: sustainable parasite control. increasing prevalence of drug-resistant gastrointestinal nematodes (GIN) [3, 4] and coccidia (Eimeria spp.) [5, $6]$, interest has been growing in use of alternative, natural methods of parasite control, including increased use of tannin-containing plants [7, 8].

Over the last 10 years, there have been a number of reports on the anti-parasitic properties of sericea lespedeza (SL; Lespedeza cuneata) in both fresh (grazed) and dried (hay, leaf meal, pellets) forms, when fed as a component of the diet to goats and sheep [7, 9-12]. This high-tannin, low-input, drought-tolerant warm-season perennial legume is 

and Nutritional Status of Grazing Goats

well-adapted to the Eastern and Southern United States (US), and other parts of the world, including Southern Africa, Asia and Australia. Its anti-parasitic properties, particularly against Haemonchus contortus, a common blood-feeding GIN, and Eimeria spp. in sheep and goats, have been attributed to its high molecular weight condensed tannins (CT), which is made up almost entirely (up to 99\%) of prodelphinidin (PD) as opposed to procyanidin (PC) tannin types [12, 13]. CT activity has been related to $\mathrm{PC} / \mathrm{PD}$ ratios, with higher anthelmintic efficacy ascribed to PD rather than PC tannins [14].

The nutritional properties of CT-containing plants are an important consideration as well, as the concept of nutraceutical feeds has gained popularity $[15,16]$. $\mathrm{SL}$ is generally considered as moderate-quality forage for livestock [17], but few authors have reported the effects of feeding SL on both animal performance and parasitic infection levels. Moore et al. [18] reported a study with parasitized and parasite-free Kiko $\times$ Spanish goat kids (six months old) fed either SL or Bermuda grass (Cynodon dactylon) hay at $75 \%$ of daily intake, with the remaining $25 \%$ as concentrate formulated to balance the rations for crude protein $(\mathrm{CP})$ and energy. Regardless of parasite status, the SL-fed kids gained $104 \mathrm{~g} / \mathrm{d}$ compared with $76 \mathrm{~g} / \mathrm{d}$ in kids fed the control diet throughout 98-day trial. Other studies have shown similar animal performance [19] or reduced growth rates in lambs or kids fed SL compared with control diets [20-22]. Few studies have examined the effects of feeding SL on serum biochemistry in sheep and goats, including micronutrient status. In a recent study with lambs fed SL diets with and without supplemental sodium molybdate, blood serum concentrations of Mo were the lowest in SL lambs, the highest in the SL + sodium molybdate animals and intermediate in control animals fed an alfalfa (Medicago sativa)-based diet [23]. The animal performance was similar between the two SL treatments and the alfalfa-based diets [19, 23].
The aim of the current investigation was to determine the effects of feeding supplemental SL leaf meal pellets on animal performance, serum micronutrient status, muscle and liver enzymes, and parasite infection status in grazing goats.

\section{Materials and Methods}

\subsection{Experimental Design}

A grazing trial with Spanish yearling bucks supplemented with SL leaf meal pellets was completed at the Fort Valley State University Agricultural Research Station from July to December, 2014.

The trial consisted of 23 Spanish yearling goats (mean 14 months old, $30.02 \pm 3.6 \mathrm{~kg}$, intact males, $n=$ 11-12 for each treatment) split into adjacent paddocks of predominantly Bermuda grass pasture for a 20 -week grazing study. Commercially-available SL leaf meal (90\%) pellets (Sims Brothers, Union Springs, AL) and a non-CT goat pellet (control group) (Mossy Creek, Mid-Georgia Farm Supply, Montezuma, GA) were fed as a supplement to treatment and control animals, respectively, at $1.5 \%$ of body weight for 14 weeks (days 0 to 98) as seen in Table 1. After 14 weeks, the goats remained in their respective adjacent paddocks, and were given only control pellets at $2.5 \%$ of body weight and supplemental Bermuda grass hay for an additional six weeks (days 99 to 137). A mineral block was provided ad libitum, containing salt $(\mathrm{NaCl})$, zinc $(\mathrm{Zn})$, iron $(\mathrm{Fe})$, manganese $(\mathrm{Mn})$, copper $(\mathrm{Cu})$, iodine (I) and cobalt (Co) at 94\%, $0.35 \%, 0.20 \%, 0.20 \%$, $0.03 \%, 0.007 \%$ and $0.005 \%$ minimum concentrations, respectively (Cargill, Inc., Minneapolis, MN).

Both pastures had similar histories, with no grazing for six months prior to the start of the study, and prior to this, grazing by similar groups of animals. Because of this, pasture parasite larvae levels were considered equivalent at the start of the study.

\subsection{Sampling and Analyses}

Fecal and blood samples were collected from 
Table 1 Chemical composition of pasture and supplemental pelleted feeds offered to grazing yearling Spanish bucks.

\begin{tabular}{lccc}
\hline \multirow{2}{*}{ Diet component } & \multicolumn{2}{c}{ Constituent $^{*}$} \\
\cline { 2 - 4 } & CP (\%) & NDF (\%) & ADF (\%) \\
\hline Pasture sample 1 (collected at the 7th week of trial in September) & & 40.6 \\
\hline Treatment & 12.2 & 59.3 & 44.5 \\
Control & 10.4 & 63.8 & 39.9 \\
\hline Pasture sample 2 (collected at the 14th week of trial in November) & & 41.9 \\
\hline Treatment & 13.1 & 56.0 & \\
Control & 11.4 & 58.4 & 22.6 \\
\hline Pellets & & 22.2 \\
\hline SL pellet (treatment) & 15.8 & 33.2 & \\
Non-CT goat pellet (control) & 17.4 & 34.0 & \\
\hline
\end{tabular}

$\mathrm{CP}=$ crude protein; $\mathrm{NDF}=$ neutral detergent fiber; $\mathrm{ADF}=$ acid detergent fiber.

${ }^{*}$ All values reported on a dry matter basis.

individual animals every $7 \mathrm{~d}$ throughout the trial to determine fecal egg count (FEC) [24] and fecal oocyst count (FOC), as well as packed cell volume (PCV), respectively. Copro-culture was conducted on bulk fecal samples (composited for each treatment group) taken on day 49 of the study to identify GIN genera, as described by Terrill et al. [10]. Additional blood samples were collected at the start of the trial and on days 98 and 137 of the experiment, and processed to recover serum for micronutrient and enzyme activity analysis. These samples were centrifuged at 4,000 $\times \mathrm{g}$ for $10 \mathrm{~min}$ on a Marathon 22KBR refrigerated centrifuge (Fisher Scientific, Waltham, MA), and serum then recovered, packaged, sealed with parafilm and sent to the Diagnostic Center for Population and Animal Health (DCPAH) at Michigan State University (MSU, Lansing, MI) for analysis of micronutrients ( $\mathrm{Se}, \mathrm{Co}, \mathrm{Fe}, \mathrm{Cu}, \mathrm{Mo}, \mathrm{Zn}$ ) and enzymes related to liver function and muscle turnover (alanine aminotransferase (ALT), aspartate aminotransferase (AST) and creatine kinase (CK)).

FAMACHA $^{\odot}$ scores [25] were determined at the times of sampling as an additional indicator of anemia status. Any animal with a FAMACHA ${ }^{\odot}$ score of 4 or 5 was dewormed using an effective dewormer -moxidectin of $0.2 \mathrm{mg} / \mathrm{kg}$ oral drench (Cydectin, Fort Dodge Animal Health, Fort Dodge, IA). Animal weights were taken on days $0,49,98$ and 140 using an electronic scale.
Pasture samples were collected from paddocks at the 7th and 14th weeks after initiation of pellet feeding using a $30.48 \mathrm{~cm}^{2}$ quadrat. Ten random samples were taken from each paddock, with plant material within the quadrat cut to $2.54 \mathrm{~cm}$ stubble height, then composited, dried at $60^{\circ} \mathrm{C}$, weighed and ground for quality analyses. Pasture sampling was discontinued after 14 weeks due to lack of available plant materials. The supplemental pellets for each treatment group were also sub-sampled and ground for analysis.

Pasture and pellet samples were analyzed for crude protein $(\mathrm{CP})$, neutral detergent fiber (NDF), and acid detergent fiber (ADF) at the DCPAH (MSU, Lansing, $\mathrm{MI}$ ), while total concentration and structure of $\mathrm{CT}$ in the SL leaf meal pellets were determined at the University of Reading, United Kingdom, using the procedure described by Gea et al. [14] with slight modification to the high-performance liquid chromatography (HPLC) analysis. HPLC analysis was carried out using an Agilent 1100 series HPLC system consisting of a G1379A degasser, G1312A binary pump, a G1313A ALS autoinjector, a G1315A diode array detector and a G1316A column oven (Agilent Technologies, Waldbronn, Germany). The column was an ACE super $\mathrm{C}_{18}$ column $(5 \mu \mathrm{m} ; 150 \mathrm{~mm} \times 3.0$ $\mathrm{mm}$; Hichrom Ltd, Theale, UK) fitted with an ACE guard column. Data were acquired using ChemStation software (version A 10.01 Rev. B.01.03). The 

and Nutritional Status of Grazing Goats

injection volume was set to $5 \mu \mathrm{L}$ and the flow rate to $0.4 \mathrm{~mL} / \mathrm{min}$. The sample was eluted using a gradient of $1 \%$ formic acid in MilliQ $\mathrm{H}_{2} \mathrm{O}$ (solvent $\mathrm{A}$ ) and HPLC-grade acetonitrile (solvent $\mathrm{B}$ ) as follows: $2.5 \%$ $\mathrm{B}$ at $0-7 \mathrm{~min}, 2.5 \%-5 \% \mathrm{~B}$ at $7-15 \mathrm{~min}, 5 \%-10 \% \mathrm{~B}$ at $15-22 \mathrm{~min}, 10 \%-40 \% \mathrm{~B}$ at $22-40 \mathrm{~min}, 40 \%-100 \%$ B at $40-45 \mathrm{~min}$ and return to $2.5 \% \mathrm{~B}$ at $49 \mathrm{~min}$. Total cycle time was 60 min with the column oven set to $60{ }^{\circ} \mathrm{C}$. Chromatograms were recorded at $280 \mathrm{~nm}$. Terminal and extension units were identified by their retention times and UV spectra.

\subsection{Statistical Analysis}

FEC, FOC, PCV, FAMACHA ${ }^{\circ}$ data, serum micronutrients, AST, ALT and CK concentrations, and animal weights were analyzed by repeated measures analysis in a completely randomized design using the mixed model procedure of SAS [26]. Treatment, period (sampling date) and the treatment $x$ period interaction were included in the model. The FEC and FOC data were log-transformed into $\ln$ (FEC $+1)$ and $\ln (\mathrm{FOC}+1)$, respectively, prior to statistical analysis. These data were reported as least squared means, with statistical inferences based upon log-transformed data analysis. Animal gains per day were analyzed as a completely randomized design using a generalized linear model (GLM) procedure of SAS [26].

\section{Results}

\subsection{Chemical Composition of Pasture Samples and} Feed Pellets

Available pasture was slightly higher in $\mathrm{CP}$ for the treatment goats compared with the control animals ( $12.2 \%$ vs. $10.4 \%$ and $13.1 \%$ vs. $11.4 \%$, respectively, in September and November pasture, while control pellets were higher in CP (17.4\%) than the 90\% SL leaf meal pellets (15.8\%) (Table 1). Estimating daily pellet intake as approximately $35 \%$ of total daily intake, CP levels were very similar between available feed in each pasture (13.2\% vs. $14.0 \%$ for control and treatment goats, respectively). Fiber levels (NDF and ADF) were very similar for both control and treatment diets (Table 1). The SL pellets also had a very high level of total CT (13.7 g CT/100 g pellets), consisting of nearly pure PD-type tannins $(99.2 \%)$ with a mean degree of polymerization of 30 (i.e., an average molecular weight of 9,183 Daltons).

\subsection{H. contortus Larvae in Copro-cultures}

Less than half of the larvae which were recovered from copro-cultures prepared from bulk fecal samples collected on day 49 of the trial were $H$. contortus $(35 \%$ and $40 \%$ for bucks supplemented with SL pellets and control pellets, respectively). Remaining larvae were a combination of Trichostrongulus colubriformis, Teladorsagia circumcincta and Cooperia spp..

\subsection{GIN Eggs}

There was a period effect $(P<0.001)$, but no treatment $(P=0.318)$ or treatment $\times$ period $(P=0.217)$ effects on GIN eggs in feces of yearling bucks fed supplemental SL pellets on pasture (Fig. 1). From day 14 through day 63, average FEC of the goats fed supplemental SL pellets were $47.1 \%$ lower than FEC of the control pellet-supplemented animals, but these differences were not significant. The FEC of control animals averaged 50\% lower than previous levels from days 70 to 95, and FEC of both the treatment and control bucks increased once SL pellet supplementation ended on day 98 (Fig. 1).

\subsection{Eimeria spp. Oocysts}

Feeding SL leaf meal pellets reduced coccidial oocyst excretion in the goats, with significant treatment $(P<0.05)$, period $(P<0.001)$ and treatment $\times$ period $(P<0.01)$ effects. The Eimeria spp. oocysts of feces from SL pellet-supplemented bucks were lower $(P<0.05)$ than in goats given control pellets on days 39-49 and on days 70-84 (Fig. 2). There were no differences in FOC between treatment groups from days 98 to 137 . 


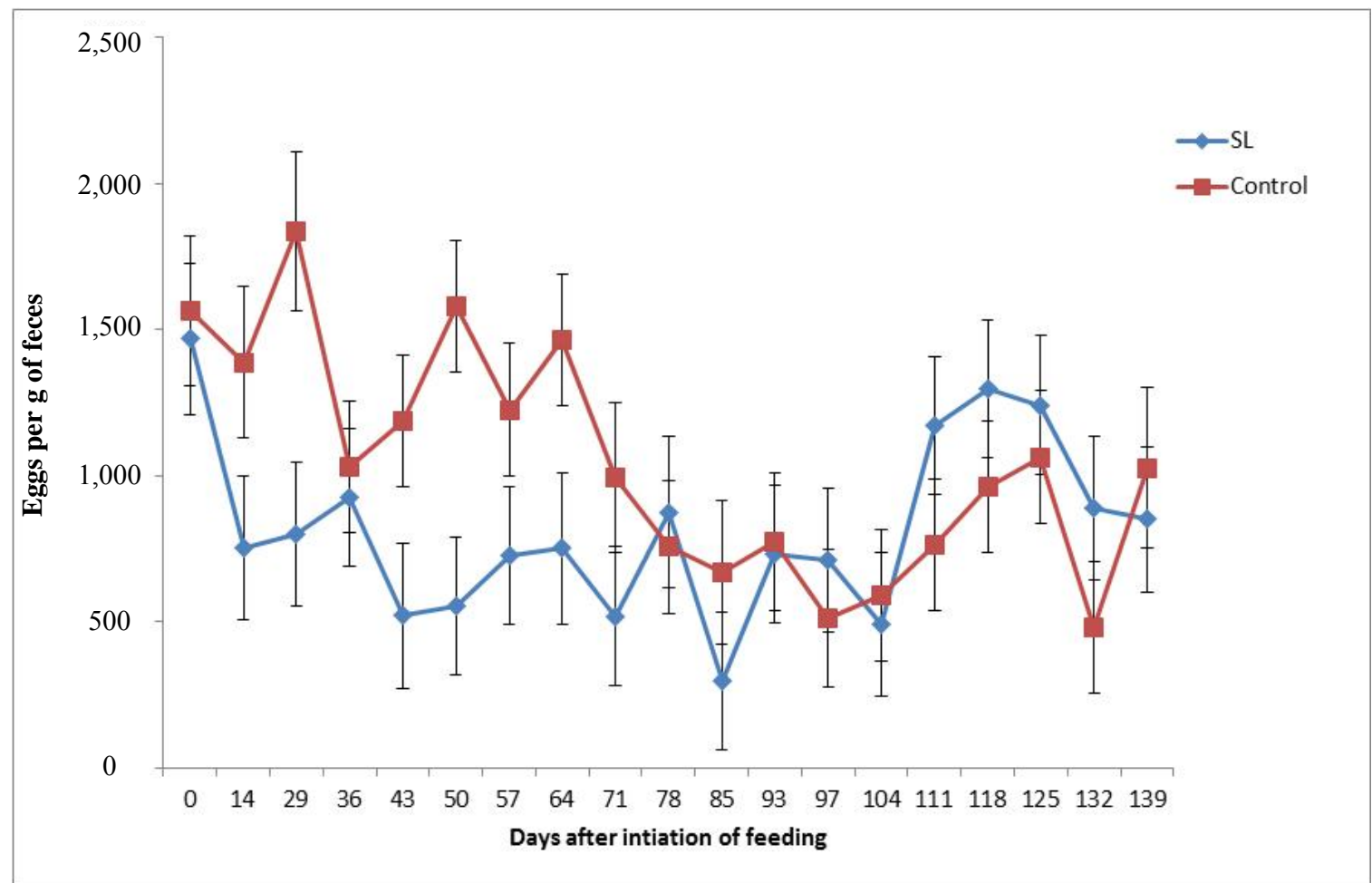

Fig. 1 Least squares means ( \pm standard error) of fecal egg counts of yearling Spanish bucks fed supplemental SL leaf meal pellets or control pellets on grass pasture.

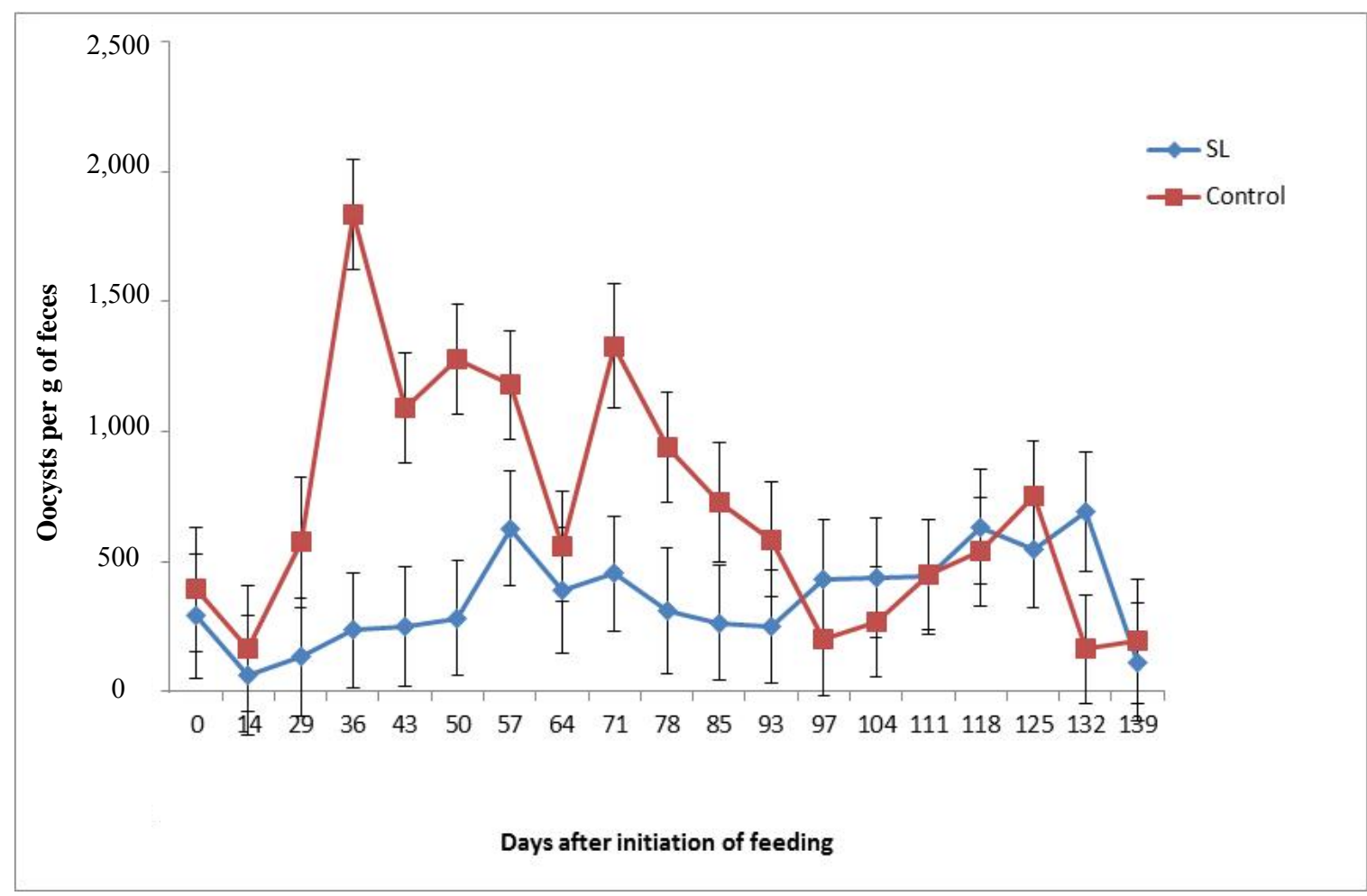

Fig. 2 Least squares means ( \pm standard error) of fecal oocyst counts of yearling Spanish bucks fed supplemental SL leaf meal pellets or control pellets on grass pasture. 

and Nutritional Status of Grazing Goats

\subsection{PCV and FAMACHA ${ }^{\odot}$}

There were significant effects of period $(P<0.001)$ and treatment $\times$ period $(P<0.01)$ on blood PCV of the goats. There were no treatment differences in PCV at the start (days 0 to 35) and end (days 123 to 130) of the study, but feeding supplemental SL leaf meal pellets to grazing bucks improved their blood PCV compared with control animals $(P<0.05)$ on days $39,63,84,95$ and 116 (Fig. 3). FAMACHA ${ }^{\odot}$ data mirrored the PCV results, with significant treatment $(P<0.001)$ and period $(P<0.001)$ effects, while there was a trend $(P$ $<0.10$ ) for the treatment $\times$ period interaction, with lower $(P<0.05)$ values (improved anemia scores) for SL pellet-supplemented bucks than those given control pellets on days 35, 39, 63, 70 and 77 (Fig. 4).

\subsection{Body Weights and Gain per Day}

There were no significant treatment $(P=0.446)$ or treatment $\times$ period $(P=0.184)$ effects of on body weight of the bucks throughout the trial (Fig. 5), but average daily gain tended to be higher $(P=0.07)$ in the treatment group (bucks given supplemental SL leaf meal pellets) compared with control animals during the initial seven weeks of the trial (days 0 to 49) (Table 2). There were no treatment differences in average daily gain from days 50 to 98 of the SL-feeding period or during the control pellet only feeding period (days 99 to 140 ).

\subsection{Mineral Analysis}

Feeding supplemental SL pellets to yearling bucks grazing grass pasture (with access to mineral blocks; Champion's Choice, Cargill, Inc., Minneapolis, MN) reduced $(P<0.05)$ serum $\mathrm{Se}$ and $\mathrm{Zn}$ concentrations, but had no effect on serum $\mathrm{Mo}, \mathrm{Co}, \mathrm{Cu}$ or Fe levels compared with bucks given supplemental non-CT (control) pellets (Table 3). Once SL pellet feeding was discontinued, all treatment differences in serum micronutrient levels disappeared, as both treatment and control groups had similar concentrations of Se, $\mathrm{Mo}, \mathrm{Zn}, \mathrm{Co}, \mathrm{Cu}$ and $\mathrm{Fe}$ at the end of the trial (Table 3).

\subsection{Liver/Enzyme Analysis}

There was no significant effect of supplemental pellet feeding treatment on ALT, AST activity and CK serum concentrations in the bucks (Table 4).

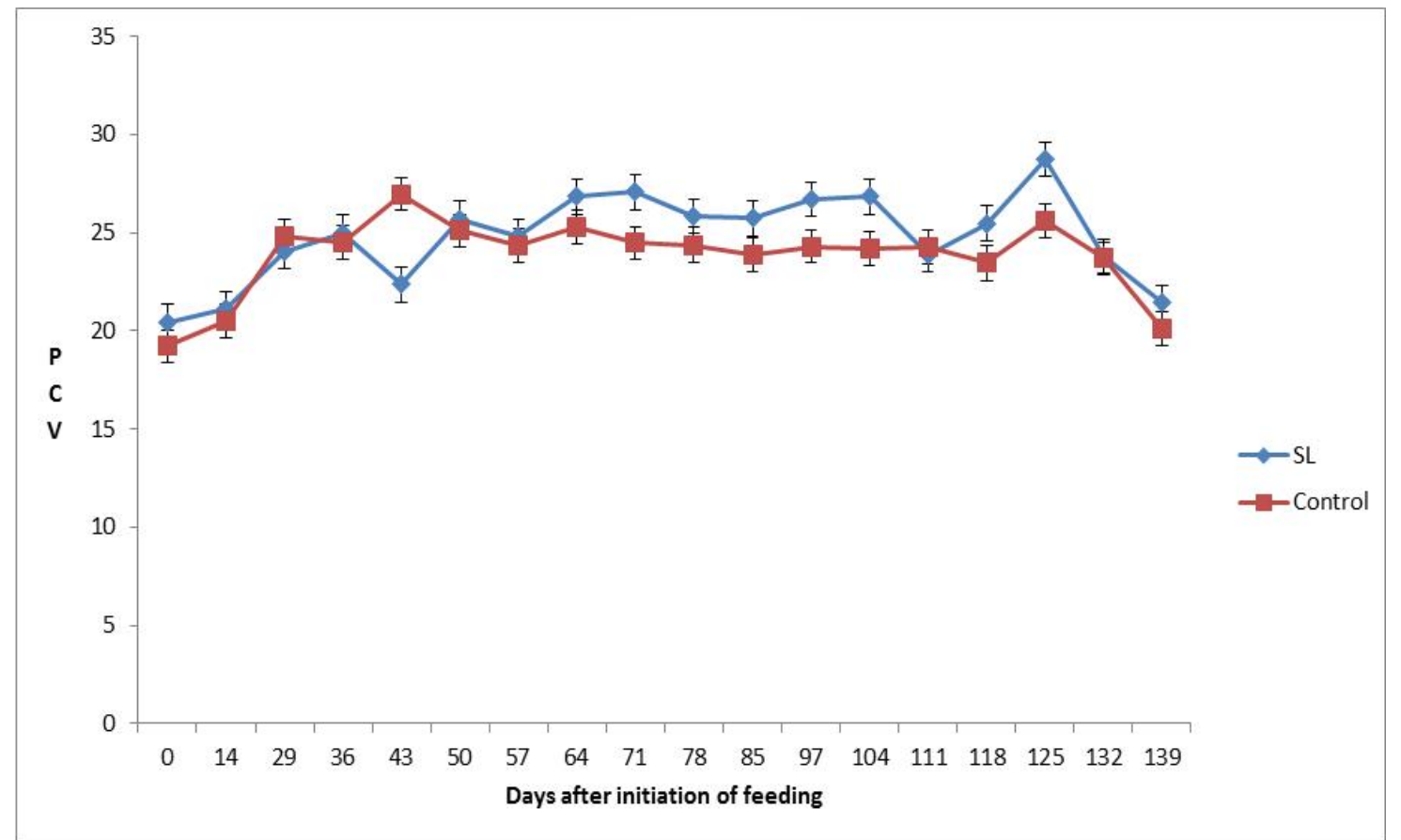

Fig. 3 Least squares means ( \pm standard error) of blood PCV of yearling Spanish bucks fed supplemental SL leaf meal pellets or control pellets on grass pasture. 


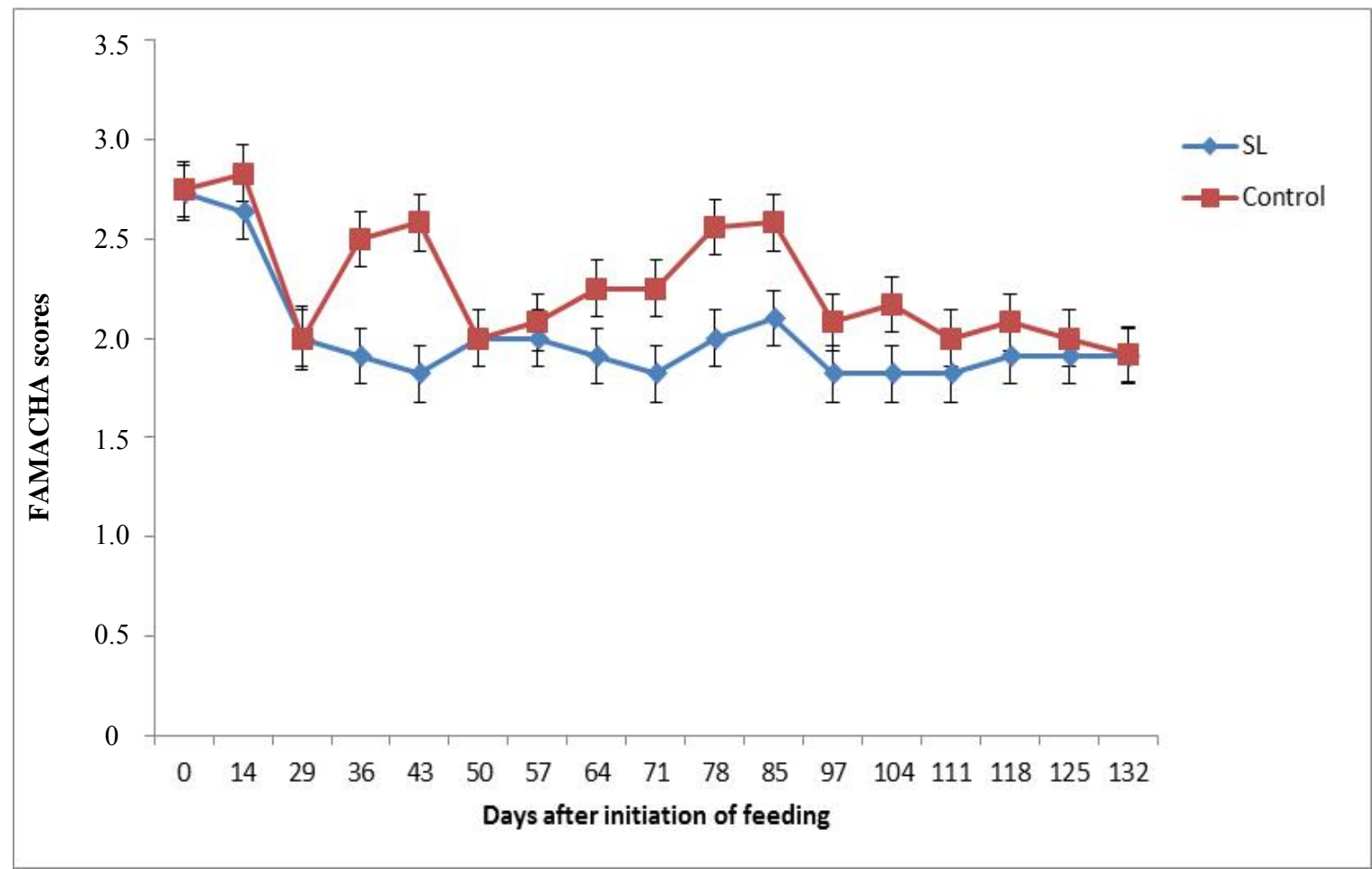

Fig. 4 Least squares means ( \pm standard error) of FAMACHA $\odot$ scores of yearling Spanish bucks fed SL leaf meal pellets or control pellets on grass pasture.

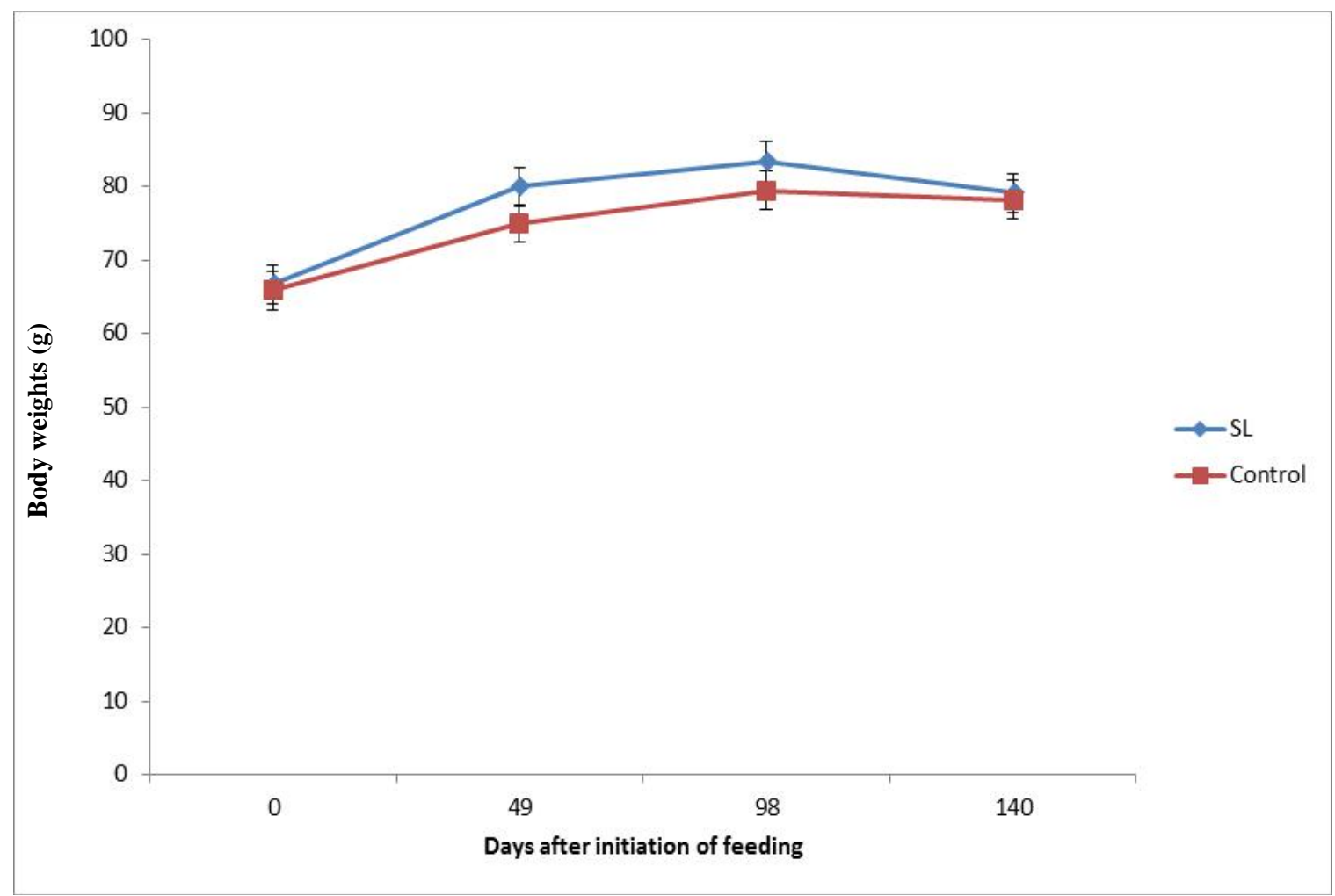

Fig. 5 Least squares means ( \pm standard error) of body weights of yearling Spanish bucks fed supplemental SL leaf meal pellets or control pellets on grass pastures. 
Table 2 Least squares means ( \pm standard error) of average daily gain (g) of yearling Spanish goats fed SL leaf meal pellets or control pellets on grass pasture.

\begin{tabular}{llll}
\hline \multirow{2}{*}{ Treatment } & \multicolumn{2}{c}{ Gain per day $(\mathrm{g})$} \\
\cline { 2 - 4 } & Days 0 to 9 & Days 50 to 98 & Days 0 to 140 \\
\hline SL pellet & $123.0 \pm 17.5$ & $37.8 \pm 9.3$ & $86.9 \pm 11.1$ \\
Control pellet & $76.6 \pm 16.7$ & $56.8 \pm 8.9$ & $72.6 \pm 10.6$ \\
\hline
\end{tabular}

Table 3 Effect of SL leaf meal pellet or control pellet supplementation on serum micronutrient status of yearling bucks grazing grass pastures.

\begin{tabular}{|c|c|c|c|c|c|c|}
\hline \multirow{3}{*}{ Micronutrient } & \multicolumn{6}{|c|}{ Days following initiation of feeding } \\
\hline & \multicolumn{2}{|c|}{ Day 0} & \multicolumn{2}{|c|}{ Day 98} & \multicolumn{2}{|c|}{ Day 137} \\
\hline & SL & Control & SL & Control & SL & Control \\
\hline $\mathrm{Se}(\mathrm{ng} / \mathrm{mL})$ & 54.00 & 44.00 & $40.00^{\mathrm{a}}$ & $58.00^{\mathrm{b}}$ & 45.00 & 48.00 \\
\hline $\mathrm{Co}(\mathrm{ng} / \mathrm{mL})$ & 2.93 & 2.61 & 1.75 & 1.87 & 1.63 & 1.27 \\
\hline $\mathrm{Cu}(\mu \mathrm{g} / \mathrm{mL})$ & 0.88 & 0.81 & 0.64 & 0.63 & 0.69 & 0.65 \\
\hline $\mathrm{Zn}(\mu \mathrm{g} / \mathrm{mL})$ & 2.54 & 3.01 & $1.38^{\mathrm{a}}$ & $3.37^{\mathrm{b}}$ & 1.01 & 1.32 \\
\hline $\mathrm{Fe}(\mu \mathrm{g} / \mathrm{dL})$ & - & - & 96.00 & 95.00 & 80.00 & 93.00 \\
\hline Mo (ng/mL) & 1.4 & 2.40 & 1.01 & 1.33 & 2.33 & 2.48 \\
\hline
\end{tabular}

Means with different superscripts in a row was significantly different at $P<0.05$.

Table 4 Effect of SL leaf meal or control pellet supplementation on liver/blood enzymes of yearling bucks grazing grass pastures.

\begin{tabular}{|c|c|c|c|c|c|c|}
\hline \multirow{3}{*}{ Enzymes } & \multicolumn{6}{|c|}{ Days following initiation of feeding } \\
\hline & \multicolumn{2}{|c|}{ Day 0} & \multicolumn{2}{|c|}{ Day 98} & \multicolumn{2}{|c|}{ Day 137} \\
\hline & $\overline{\mathrm{SL}}$ & Control & $\overline{\mathrm{SL}}$ & Control & $\overline{\mathrm{SL}}$ & Control \\
\hline $\operatorname{ALT}(\mu \mathrm{kat} / \mathrm{L})$ & 0.012 & 0.011 & 0.011 & 0.012 & 0.011 & 0.010 \\
\hline $\operatorname{AST}(\mu \mathrm{kat} / \mathrm{L})$ & 0.403 & 0.330 & 0.340 & 0.318 & 0.260 & 0.235 \\
\hline $\mathrm{CK}(\mu \mathrm{kat} / \mathrm{L})$ & 1.374 & 1.336 & 1.683 & 1.491 & 1.380 & 1.255 \\
\hline
\end{tabular}

ALT: alanine aminotransferase; AST: aspartate aminotransferase; CK: creatine kinase.

\section{Discussion}

Feeding supplemental SL leaf meal pellets to yearling Spanish bucks grazing perennial, warm-season, grass-based pasture in late summer-early autumn reduced the infection with internal parasites, confirming previous reports describing the anti-parasitic effects of feeding SL as a pasture supplement to kids as pellets [27]. There was no treatment effect on FEC, but there was a reduction in FOC and improved anemia (PCV) and FAMACHA ${ }^{(}$ scores in the SL pellet-supplemented bucks in the current study. The improved anemia results suggest a positive effect against $H$. contortus, as this is the primary blood-feeding GIN in small ruminants, although the PCV and FAMACHA ${ }^{\circledR}$ scores were not statistically significant until days 35 to 39 of pellet supplementation. Similar results (delayed effects on anemia scores) of feeding SL hay [18] or pellets [10] to goats in confinement have been reported previously. The lack of a treatment effect on FEC in the bucks in the current trial may have been related to the level of SL intake or the $H$. contortus infection levels in these animals. In previous reports, in which SL hay, leaf meal or pellets were fed to goats in confinement $[7,10$, 28, 29] or as supplemental pellets on pasture [27] at $37.5 \%$ of the diet or higher, significant reductions in nematode FEC have been reported. However, Terrill et al. [28] reported no effect of SL hay on FEC of goats when fed at $18.8 \%$ of the diet. Although total intake was not measured in the current investigation, pellets were initially fed at $1.5 \%$ of body weight, which was estimated to be approximately $35 \%$ of the goats' daily 
intake. In addition, as SL is more effective against $H$. contortus than other GIN species [7], the positive anti-parasitic effects of SL have been reported to be reduced or delayed, when $H$. contortus is not the predominant infection, as often occurs in cooler months in Georgia [28].

The treatment differences in FOC occurred due to a rapid rise in these values in the control goats after day 28 of the trial, while the FOC of SL-supplemented animals remained low (Fig. 2). These differences disappeared over the last 2-3 weeks of the SL pellet supplementation period and after SL pellet supplementation was discontinued (Fig. 2). This appears to be due to a reduction in FOC values in the control animals rather than any change in these values in the SL pellet-supplemented bucks. A similar short-term advantage of feeding SL pellets on FOC in goats has been reported previously in animals given SL leaf meal or commercial pellets as their sole diet [13]. The treatment differences in the current investigation occurred, despite SL pellets being a much lower component of the diet. This suggests that lower levels of dietary SL may have a greater effect on coccidia than GIN in goats.

In addition to short-term positive anti-parasitic effects of supplementing grazing bucks with SL leaf meal pellets, there was also a positive initial effect on animal performance, with a trend toward higher $(P=$ 0.07 ) weight gain per day over days 0 to 49 , compared with animals supplemented with a non-CT control goat pellet (Table 2). Gujja et al. [27] reported increased weight gains in goats supplemented with a 95\% SL leaf meal pellet on pasture compared with a commercial pellet, while there was no benefit to feeding a $75 \%$ SL pellet. The treatment pellets used in the current study consisted of $90 \%$ SL leaf meal. Any differences in animal performance in this study are more likely due to $\mathrm{CT}$ intake than $\mathrm{CP}$ intake between SL-treatment than control goats. Although intake was not measured in this investigation, CP intake was likely similar between the groups, as lower pasture $\mathrm{CP}$ in the control group would have been offset by higher $\mathrm{CP}$ in the pellet portion of the diet (Table 1). Weight gain per day slowed considerably for both treatment groups for the second seven weeks of SL pellet supplementation (days 50 to 98 ) and after SL pellet feeding was discontinued (days 99 to 137) (Table 2). This may have been due to slowed growth rate of the bucks, due to increased maturity (16-19 months old) or reduced pasture availability that required supplementing with Bermuda grass hay.

Slowing of growth rate of goats and sheep from long-term feeding of SL pellets has been reported by other authors [21,22] and been suggested to be related to negative effects on micronutrient status in the animal, particularly Mo, Se and $\mathrm{Zn}[19,23]$. This did not appear to be the case in the current study for serum Mo, but serum concentrations of $\mathrm{Se}$ and $\mathrm{Zn}$ were reduced by day 98 (Table 3). However, this did not appear to have any negative effect on animal performance (gain per day).

There were also no treatment effects on enzymes related to liver function (ALT and AST) and muscle turnover (CK) in the bucks (Table 4), suggesting that there was no muscle or liver damage due to long-term feeding of SL pellets in this study. Acharya et al. [19] reported elevated AST levels in lambs fed an SL-based diet compared with an alfalfa-based control diet and suggested that SL feeding may relieve heat stress in animals. This could not be confirmed in the current investigation, which occurred during cooler months, but this may be an important consideration for future studies with SL.

\section{Conclusions}

Feeding supplemental SL pellets on pasture had a variable effect on both parasite infection and nutritional status of yearling goats. There were short-term improvements (approximately nine weeks) in animal performance and infection status in goats fed supplemental SL pellets, whereas long-term feeding resulted in similar animal performance as 

and Nutritional Status of Grazing Goats

goats given supplemental non-CT (control) pellets. Parasite/nutrition effects in this study do not appear to be related to micronutrient status or concentration of enzymes related to liver function and muscle turnover in the goats. Short-term feeding of supplemental SL pellets on pasture may improve performance and parasitic infection status of goats, and should be a viable option for farmers during the parasite season. Additional research is needed to determine the long-term effects of SL feeding on nutrition-parasite interactions in livestock.

\section{Acknowledgments}

This material is based upon work supported by the National Institute of Food and Agriculture, U.S. Department of Agriculture, under award numbers 2011-33610-30836 and 2010-51300-21641.

\section{References}

[1] Gatongi, P. M., Scott, M. E., Ranjan, S., Gathuma, J. M., Munyua, W. K., Cheruiyot, H., and Prichard, R. K. 1997. "Effects of Three Nematode Anthelmintic Treatment Regimes on Flock Performance of Sheep and Goats under Extensive Management in Semi-arid Kenya." Vet. Parasitol. 68 (4): 323-36.

[2] Hoskin, S. O., Wilson, P. R., Barry, T. N., Charleston, W. A. G., and Waghorn, G. C. 2000. "Effect of Forage Legumes Containing Condensed Tannins on Lungworm (Dictyocaulus sp.) and Gastrointestinal Parasitism in Young Red Deer (Cervus elaphus).” Res. Vet. Sci. 68 (3): 223-30.

[3] Kaplan, R. M. 2004. "Drug Resistance in Nematodes of Veterinary Importance: A Status Report." Trends Parasitol. 20 (10): 477-81.

[4] Howell, S. B., Burke, J. M., Miller, J. E., Terrill, T. H., Valencia, E., Williams, M. J., Williamson, L. H., Zajac, A. M., and Kaplan, R. M. 2008. "Prevalence of Anthelmintic Resistance on Sheep and Goat Farms in the Southeastern United States.” J. Am. Vet. Med. Assoc. 233 (12): 1913-9.

[5] Haberkorn, A. 1996. "Chemotherapy of Human and Animal Coccidiosis: State and Perspectives." Parasitol. Res. 82 (3): 193-9.

[6] Greif, G., Stephan, B., and Haberkorn, A. 1996. "Intraspecific Polymorphisms of EimeriaSpecies due to Resistance due to Coccidial Drugs." Parasitol. Res. 82 (8): 706-14.

[7] Shaik, S. A., Terrill, T. H., Miller, J. E., Kouakou, B.,
Kannan, G., Kaplan, R. M., Burke, J. M., and Mosjidis, J. A. 2006. "Sericea Lespedeza Hay as a Natural Deworming Agent against Gastrointestinal Nematode Infection in Goats." Vet. Parasitol. 139: 150-7.

[8] Githiori, J. B., Spiridoula, A., and Thamsborg, S. M. 2006. "Use of Plants in Novel Approaches for Control of Gastrointestinal Helminths in Livestock with Emphasis on Small Ruminants." Vet. Parasitol. 139 (4): 308-20.

[9] Lange, K. C., Olcott, D. D., Miller, J. E., Mosjidis, J. A., Terrill, T. H., Burke, J. M., and Kearney, M. T. 2006. "Effect of Sericea Lespedeza (Lespedeza cuneata), Fed as Hay, on Natural and Experimental Haemonchus contortus Infections in Lambs." Vet. Parasitol. 141 (3-4): 273-8.

[10] Terrill, T. H., Mosjidis, J. A., Moore, D. A., Shaik, S. A., Miller, J. E., Burke, J. M., Muir, J. P., and Wolfe, R. 2007. "Effect of Pelleting on Efficacy of Sericea Lespedeza Hay as a Natural Dewormer in Goats." Vet. Parasitol. 146 (1-2): 117-22.

[11] Terrill, T. H., Miller, J. E., Burke, J. M., Mosjidis, J. A., and Kaplan, R. M. 2012. "Experiences with Integrated Concepts for the Control of Haemonchus contortus in Sheep and Goats in the United States." Vet. Parasitol. 186 (1-2): 28-37.

[12] Mechineni, A., Kommuru, D. S., Gujja, S., Mosjidis, J. A., Miller, J. E., Burke, J. M., Ramsay, A., Mueller-Harvey, I., Kannan, G., Lee, J. H., Kouakou, B., and Terrill, T. H. 2014. "Effect of Fall-Grazed Sericea Lespedeza (Lespedeza cuneata) on Gastrointestinal Nematode Infections of Growing Goats.” Vet. Parasitol. 204 (3-4): 221-8.

[13] Kommuru, D. S., Barker, T., Desai, S., Burke, J. M., Ramsay, A., Mueller-Harvey, I., Miller, J. E., Mosjidis, J. A., Kamisetti, N., and Terrill, T. H. 2014. "Use of Pelleted Sericea Lespedeza (Lespedeza cuneata) for Natural Control of Coccidia and Gastrointestinal Nematodes in Weaned Goats." Vet. Parasitol. 204 (3-4): 191-8.

[14] Gea, A., Stringano, E., Brown, R., and Mueller-Harvey, I. 2011. "In Situ Analysis and Structural Elucidation of Sainfoin (Onobrychis viciifolia) Tannins for High-Throughput Germplasm Screening." J. Agric. Food Chem. 59 (2): 495-503.

[15] Andlauer, W., and Fürst, P. 2002. "Nutraceuticals: A Piece of History, Present Status and Outlook." Food Res. Int. 35 (2): 171-6.

[16] Hoste, H., Jackson, F., Athanasiadou, S., Thamsborg, S. M., and Hoskin, S. O. 2006. "The Effects of Tannin-Rich Plants on Parasitic Nematodes in Ruminants." Trends Parasitol. 22 (6): 253-61.

[17] Hoveland, C. S., Windham, W. R., Boggs, D. L., Durham, R. G., Calver, G. V., Newsome, J. F., Dobson Jr., J. W., and Owsley, M. 1990. Sericea Lespedeza Production in Georgia. Athens: College of Agriculture, University of 
Georgia.

[18] Moore, D. A., Terrill, T. H., Kouakou, B., Shaik, S. A., Mosjidis, J. A., Miller, J. E., Vanguru, M., Kannan, G., and Burke, J. M. 2008. "The Effects of Feeding Sericea Lespedeza Hay on Growth Rate of Goats Naturally Infected with Gastrointestinal Nematodes.” J. Anim. Sci. 86 (9): 2328-37.

[19] Acharya, M., Burke, J. M., Coffey, K. P., Kegley, E. B., Miller, J. E., Huff, G. R., Smyth, E., Terrill, T. H., Mosjidis, J. A., and Rosenkrans, C. 2015. "Changes in Hematology, Serum Biochemistry and Gastrointestinal Nematode Infection in Lambs Fed Sericea Lespedeza." J. Anim. Sci. 93 (4): 1952-61.

[20] Turner, K. E., Wildeus, S., and Collins, J. R. 2005. "Intake, Performance and Blood Parameters in Young Goats Offered High Forage Diets of Lespedeza or Alfalfa Hay." Small Rumin. Res. 59 (1): 15-23.

[21] Burke, J. M., Miller, J. E., Mosjidis, J. A., and Terrill, T. H. 2012. "Use of a Mixed Sericea Lespedeza and Grass Pasture System for Control of Gastrointestinal Nematodes in Lambs and Kids.” Vet. Parasitol. 186 (3-4): 328-36.

[22] Burke, J. M., Miller, J. E., Terrill, T. H., and Mosjidis, J. A. 2014. "The Effects of Supplemental Sericea Lespedeza Pellets in Lambs and Kids on Growth Rate." Livest. Sci. 159: 29-36.

[23] Acharya, M., Burke, J. M., Coffey, K. P., Kegley, E. B., Miller, J. E., Smyth, E., Welborn, M. G., Terrill, T. H., Mosjidis, J. A., and Rosenkrans, C. 2016. "Changes in
Concentrations of Trace Minerals in Lambs Fed Sericea Lespedeza Leaf Meal Pellets with or without Dietary Sodium Molybdate.” J. Anim. Sci. 94 (4): 1592-9.

[24] Whitlock, H. V. 1948. "Some Modifications of the McMaster Helminth Egg Counting Technique and Apparatus.” J. Coun. Sci. Indust. Res. 21 (3): 177-80.

[25] Van Wyk, J. A., and Bath, G. F. 2002. "The FAMACHA System for Managing Haemonchosis in Sheep and Goats by Clinically Identifying Individual Animals for Treatment." Vet. Res. 33 (5): 509-29.

[26] SAS Institute. 2008. SAS/STAT Software: Changes and Enhancements through Release 9.2. Cary, NC: SAS Institute.

[27] Gujja, S., Terrill, T. H., Mosjidis, J. A., Miller, J. E., Mechineni, A., Kommuru, D. S., Shaik, S. A., Lambert, B. D., Cherry, N. M., and Burke, J. M. 2013. "Effect of Supplemental Sericea Lespedeza Leaf Meal Pellets on Gastrointestinal Nematode Infection in Grazing Goats." Vet. Parasitol. 191 (1-2): 51-8.

[28] Terrill, T. H., Dykes, G. S., Shaik, S. A., Miller, J. E., Kouakou, B., Kannan, G., Burke, J. M., and Mosjidis, J. A. 2009. "Efficacy of Sericea Lespedeza Hay as a Natural Dewormer in Goats: Dose Titration Study." Vet. Parasitol. 163 (1-2): 52-6.

[29] Joshi, B. R., Kommuru, D. S., Terrill, T. H., Mosjidis, J. A., Burke, J. M., Shakya, K. P., and Miller, J. E. 2011. "Effect of Feeding Sericea Lespedeza Leaf Meal in Goats Experimentally Infected with Haemonchus contortus." Vet. Parasitol. 178 (1-2): 192-7. 